\title{
The Distressing Overuse of Gastric Acid Inhibitors
}

\author{
Reidar Fossmark $\cdot$ Helge Waldum
}

Received: 6 December 2012/Accepted: 18 December 2012/Published online: 10 January 2013

(c) Springer Science+Business Media New York 2013

Gastric acid secretion by parietal cells is an energy consuming process that concentrates $\mathrm{H}+$ one million-fold. The energy required is produced by abundant mitochondria. High gastric acidity in combination with the proteolytic enzyme, pepsin, and the lipolytic enzyme, lipase, plays a key role in killing ingested microorganisms including bacteria [1, 2], viruses [3], and prions [4]. This corrosive juice can, however, overwhelm mucosal defense mechanisms leading to erosion and ulceration.

Stress ulcers and less severe damage to the gastric mucosa may develop in critically ill patients. The damage, which occurs predominantly in the oxyntic mucosa, is thought to be caused by tissue hypoxia [5, 6]. Hypovolemic or hypotensive patients are at obvious risk of developing such ulcers, but severe illness also increases the risk of stress ulcers [7, 8], particularly in patients requiring mechanical ventilation. Experimental studies have suggested that antisecretory medications, e.g. proton pump inhibitors (PPIs) and histamine $\mathrm{H}_{2}$-receptor antagonists $\left(\mathrm{H}_{2} \mathrm{RAs}\right)$, reduce development of ulcers in the oxyntic mucosa by decreasing energy expenditure as well as raising intragastric $\mathrm{pH}[9,10]$.

In this issue of Digestive Diseases and Sciences, Koczka et al. [11] report the overuse of stress ulcer prophylaxis in a large medical center. This adds to a large body of literature reporting the inappropriate overprescription of PPIs.

R. Fossmark · H. Waldum ( $₫)$

Department of Gastroenterology and Hepatology, St. Olavs

Hospital, Prinsesse Kristinas Gate 1, 7006 Trondheim, Norway

e-mail: helge.waldum@ntnu.no

R. Fossmark $\cdot$ H. Waldum

Department of Cancer Research and Molecular Medicine,

Norwegian University of Science and Technology, Prinsesse

Kristinas Gate 1, 7006 Trondheim, Norway
Although the use of gastric acid inhibitors may reduce the risk of stress ulcers, it is important to target the therapy to patients at significant risk since PPIs have recently been associated with numerous adverse events, including infections. Gastric hypoacidity leads to bacterial overgrowth in the stomach and small intestine, in particular, an increase in gram negative and anaerobic bacteria [12, 13]. PPIs also increase the risk for Clostridium difficile infection (CDI) [14] and may predispose cirrhotic patients for spontaneous bacterial peritonitis $[15,16]$. PPIs may also be associated with increased risk for respiratory infections, although the data are less clear [17, 18]. Nevertheless, in patients disposed to develop stress ulcers (that is patients with hypovolemia and/or hypoxia), it seems justified to prescribe prophylaxis with PPIs since the benefits of preventing a significant bleed in these very sick patients outweigh potential risks [19]. Critically ill patients probably profit from PPI stress ulcer prophylaxis, whereas in less ill patients with a minute risk of development of stress ulcers, the side effects may represent a greater risk for the patients than a possible small reduction in the risk of stress ulcer bleeding. In the present issue Koczka et al. [11] compared the attitude to stress ulcer prophylaxis between attending physicians and residents in a medical center in New York, reporting that half of the attending physicians thought that stress ulcer prophylaxis was indicated outside critical care settings.

Perhaps even more problematic than short-term overuse of PPIs during the hospital stay is the fact that most of these patients are discharged on PPIs and thus probably remain on these drugs for prolonged periods without a proper indication [20, 21]. After patients are on PPIs for more than 3 months, stopping may be difficult due to rebound acid hypersecretion-induced dyspepsia [22, 23].

In conclusion, stress ulcer prophylaxis with PPIs is indicated in critically ill patients with hypovolemia and/or 
tissue hypoxia since these patients are predisposed to stress ulcer bleeding and PPIs are the most effective agents to prevent this complication. As PPIs have recently been associated with a plethora of adverse events, including increased infection rates, these medications should be given for specific indications and for the least time necessary.

\section{References}

1. Martinsen TC, Bergh K, Waldum HL. Gastric juice: a barrier against infectious diseases. Basic Clin Pharmacol Toxicol. 2005; 96:94-102.

2. Wilder-Smith $\mathrm{CH}$, Spirig C, Krech T, Merki H. Bactericidal factors in gastric juice. Eur J Gastroenterol Hepatol. 1992;4: 885-891.

3. Weiss C, Clark HF. Rapid inactivation of rotaviruses by exposure to acid buffer or acidic gastric juice. J Gen Virol. 1985;66: 2725-2730.

4. Martinsen TC, Benestad SL, Moldal T, Waldum HL. Inhibitors of gastric acid secretion increase the risk of prion infection in mice. Scand J Gastroenterol. 2011;46(12):1418-1422. doi:10.3109/ 00365521.2011 .619277$.

5. Sethbhakdi S, Pfeiffer CJ, Roth JL. Gastric mucosal ulceration following vasoactive agents. A new experimental model. Am J Dig Dis. 1970;15:261-270.

6. Menguy R, Masters YF. Mechanism of stress ulcer. 3. Effects of hemorrhagic shock on energy metabolism in the mucosa of the antrum, corpus, and fundus of the rabbit stomach. Gastroenterology. 1974;66:1168-1176.

7. Brown TH, Davidson PF, Larson GM. Acute gastritis occurring within 24 hours of severe head injury. Gastrointest Endosc. 1989; 35:37-40.

8. Cook D, Heyland D, Griffith L, Cook R, Marshall J, Pagliarello J. Risk factors for clinically important upper gastrointestinal bleeding in patients requiring mechanical ventilation. Canadian Critical Care Trials Group. Crit Care Med. 1999;27:2812-2817.

9. Waldum HL, Marvik R, Gronbech JE, Sandvik AK, Aase S. Oxyntic lesions may be provoked in the rat both by the process of acid secretion and also by gastric acidity. Aliment Pharmacol Ther. 2000;14:135-141.

10. Demitrack ES, Aihara E, Kenny S, Varro A, Montrose MH. Inhibitors of acid secretion can benefit gastric wound repair independent of luminal $\mathrm{pH}$ effects on the site of damage. Gut. 2012;61:804-811. doi:10.1136/gutjnl-2011-300420.
11. Koczka CP, Geraldino-Pardilla LB, Goodman AJ. Physicians' opinions of stress ulcer prophylaxis: survey results from a large urban medical center. Dig Dis Sci. 2012. (Epub ahead of print). doi:10.1007/s10620-012-2423-x.

12. Giannella RA, Broitman SA, Zamcheck N. Gastric acid barrier to ingested microorganisms in man: studies in vivo and in vitro. Gut. 1972;13:251-256.

13. Lewis SJ, Franco S, Young G, O'Keefe SJ. Altered bowel function and duodenal bacterial overgrowth in patients treated with omeprazole. Aliment Pharmacol Ther. 1996;10:557-561.

14. Howell MD, Novack V, Grgurich P, et al. Iatrogenic gastric acid suppression and the risk of nosocomial Clostridium difficile infection. Arch Intern Med. 2010;170:784-790. doi:10.1001/ archinternmed.2010.89.

15. Trikudanathan G, Israel J, Cappa J, O'Sullivan DM. Association between proton pump inhibitors and spontaneous bacterial peritonitis in cirrhotic patients-a systematic review and meta-analysis. Int J Clin Pract. 2011;65:674-678. doi:10.1111/j.17421241.2011.02650.x.

16. Thuluvath PJ, Morss S, Thompson R. Spontaneous bacterial peritonitis-in-hospital mortality, predictors of survival, and health care costs from 1988 to 1998. Am J Gastroenterol. 2001;96:1232-1236. doi:10.1111/j.1572-0241.2001.03708.x.

17. Prod'hom G, Leuenberger P, Koerfer J, et al. Nosocomial pneumonia in mechanically ventilated patients receiving antacid, ranitidine, or sucralfate as prophylaxis for stress ulcer. A randomized controlled trial. Ann Intern Med. 1994;120:653-662.

18. de Jager CP, Wever PC, Gemen EF, et al. Proton pump inhibitor therapy predisposes to community-acquired Streptococcus pneumoniae pneumonia. Aliment Pharmacol Ther. 2012. doi: 10.1111/apt.12069.

19. Cook DJ, Griffith LE, Walter SD, et al. The attributable mortality and length of intensive care unit stay of clinically important gastrointestinal bleeding in critically ill patients. Critical Care (London, England). 2001;5:368-375.

20. Reimer C, Bytzer P. Clinical trial: long-term use of proton pump inhibitors in primary care patients-a cross sectional analysis of 901 patients. Aliment Pharmacol Ther. 2009;30:725-732. doi: 10.1111/j.1365-2036.2009.04092.x.

21. Jacobson BC, Ferris TG, Shea TL, Mahlis EM, Lee TH, Wang TC. Who is using chronic acid suppression therapy and why? Am J Gastroenterol. 2003;98:51-58. doi:10.1111/j.1572-0241.2003. 07186.x.

22. Waldum HL, Arnestad JS, Brenna E, Eide I, Syversen U, Sandvik AK. Marked increase in gastric acid secretory capacity after omeprazole treatment. Gut. 1996;39:649-653.

23. Reimer C, Sondergaard B, Hilsted L, Bytzer P. Proton pump inhibitor therapy induces acid-related symptoms in healthy volunteers after withdrawal of therapy. Gastroenterology. 2009;137: $80-87$. 